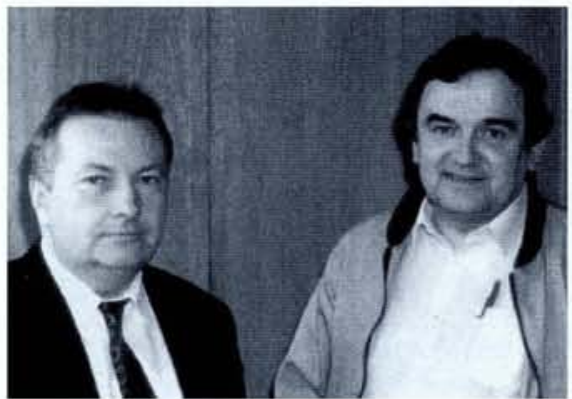

Professor Maciej Bugajski, on the left, with Professor Henryk Szymczak.

links to government-owned industry remain strong. By producing integrated circuits, both as production series and prototypes, his lab is able to function with only $60 \%$ of statutory support from its ministry whereas most need about $80 \%$. But such considerations are hopefully only for the short term and in trying to plan for the long-term, he feels that the "right way" is for the ministry labs to become national labs and for institutes and universities to broaden activities to encompass product development. He points out that a KBN mechanism involving matching contract funds with grants in fact already exists to promote this type of broadening.

\section{Readjusting Rôles}

The government appears to share Professors Hrynkiewicz and Bugajski's view that the best approach is to maintain today's scientific capacity in the long-term interest. Both agree that such thinking will determine the status and fate of research in the R\&D centres attached to the ministries. While the creation of national laboratories has been discussed in government it has not gone further perhaps because there are more urgent issues.

The Academy institutes are moving towards the universities by creating undergraduate "non-public colleges" (see insert) since PAS staff feel strongly that they have a duty to teach to remain creative scientists. Profiting from a small inertia, the keyword is interdisciplinarity although to be fair the universities have started moving in the same direction. For instance, Warsaw University combined faculties to create a year or so ago a School of Science that offers personal tutors - a new feature for Poland - and the Jagiellonian University is reviving the school system under its original title of Collegium. As far as physics is concerned, the universities reaction to the colleges is ambiguous, perhaps because their undergraduate intakes

The Institute of Physics of the Polish Academy of Sciences, Warsaw.

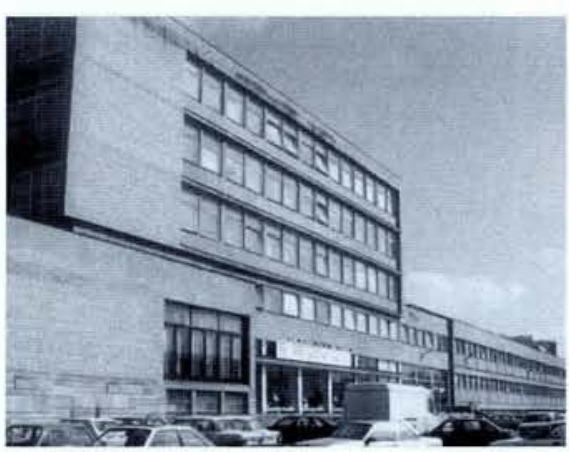

have shown strong fluctuations and variations so it is difficult to judge needs and the likely response from prospective students. In contrast to the situation at technical universities, applications dropped markedly at most classical universities several years ago as students felt they could look forward "only to either a Nobel Prize or nothing". Entry requirements and curricula have since been modified and entries are tending to increase in line with unemployment. But to complicate matters, enrollment at some universities have dropped by $50 \%$ whereas Warsaw University has seen its physics intake increase from a low point of about 100 in 1990/1 to 414 in $1992 / 3$ and 363 in $1993 / 4$, with a similar number expected for $1994 / 5$.

Many academics appreciate that the PAS institutes have a long and prestigous record in basic research. Professor Grynberg ack- nowledges that they "do good work" and he believes that a "third solution" must be found involving an "adiabatic fusion" of interests. In the case of physics, he feels difficulties cannot be so large given that only $7 \%$ of scientists doing physics work in the Academy institutes as opposed to $87 \%$ in the universities. While the universities' weight is probably overestimated (Table 2), he nonetheless places the onus on them as some "hard discussion" is needed. Professor Turski implies difficulties may be more deep-rooted since "the education system has not yet been truely overhauled".

\section{Encouraging Graduates}

As pointed out by Professor Spalek on page 54 , roughly $20 \%$ - a low percentage by west European standards - of each year's 600 master degrees in physics carry

\title{
Non-public Colleges Offer Undergraduate Courses
}

A recent softening of entry requirements in Poland meant that 140000 qualified young people applied to enter universities in 1992/3 but only 65000 were accepted for the 5-year master's degree. Faced with this demand, the first-year intake was raised to 80000 resulting in some courses becoming heavily overcrowded. But the steeply rising trend cannot continue for long as it strains both the universities and the country's scarce resources. A new initiative to increase the number of openings involves "non-public colleges" including one in science (there are also colleges in medicine, law, etc.) created by staff members of institutes of the Polish Academy of Sciences (PAS). They felt that the Academy had the flexibility and resources to provide the modern, interdisciplinary educational background that young people need in a transforming economy.

Professor Jan Mostowski (shown in the photograph) of the Centre for Theoretical Physics of the PAS in Warsaw is the Rector of the nonpublic College of Science. Supported by six PAS institutes and by the Institute of Electronic Technology attached to the Ministry of Industry and Trade, it rents equipment from universities. $\mathrm{He}$ explained that it is formally separated from the Academy, being owned by the private Stanislaw Ulam Foundation set up by several of the Academy's scientists in 1992. The College is in a sense modelled on the prestigious physical-technical university institutes attached to some of the institutes of the Russian Academy of Sciences [see Unique Russian Training

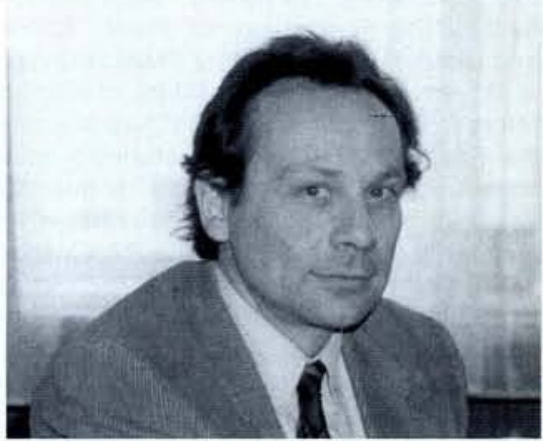
Scheme at Risk, EN 23 (1992) 71]. Teaching started last autumn with interdisciplinary studies along the lines offered since 1992 by several faculties of the University of Warsaw. The 21 firstyear students will choose courses in physics, chemistry, maths, computer science, and management for the first two years and then specialize in the third year

Academy staff used to be restricted by law to teaching at the postgraduate level (many institutes have well-established postgraduate programmes) but the government changed regulations in March 1993 to allow the College to offer the three-year bachelor's degree. The students pay fees of about ECU 900 pa, roughly 2-4 times the monthly salary of a university professor; lecturers receive some payment, but nothing exceptional in view of the considerable time and energy injected. The College has applied for full recognition to teach the 5-year master's degree and Professor Mostowski is confident that it will eventually be granted Observers from outside tend to argue that professional scientists in institutes with excellent research records should perhaps focus on research; the scientists themselves say, however, that they have a "duty to teach" as benefits pass both ways: the interaction with students sharpens a scientist's skills while students can access precious facilities, a modern research environment, and links to industry.

The College of Science will take in up to about 30 students next year. Longer-term, the various colleges could fuse to form the nucleus of a new university and go fully public if regulations governing the Academy institutes change. Pressure for this evolution arises because Warsaw University, the country's largest, only has plans under study for grouping 23 faculties, but no firm site for a modern campus to replace its scattered buildings. Meanwhile, other major universities are implementing long-established plans (Poznań University, for instance, has already partly moved to a new campus and construction of what is intended to be Jagellonian University's "Campus 2000" project on former military land in Cracow started recently). 
on to 3-4 year PhDs. Professor Niewodniczański estimates that about $5 \%$ of physics graduates now move out of the country for their PhD studies; others leave before completing them. Professor Spalek emphasizes the need to attract and retain a critical number of young people who are recognized internationally by their research and will be strongly committed to lead others. Recent measures to do this include Warsaw University's grants in the second year of graduate studies, to attend conferences and schools, and graduate scholarships offered by the Foundation for the Development of Science. Indeed some professors (jokingly?) complain that their best students earn more than they do (a full-professor currently earns a basic gross monthly salary of ECU $350-400$ without income from grants, as compared to ECU 200-300 for school teachers and up to ECU 900 for managers in industry).

In spite of its economic difficulties, Poland has managed to install a comprehensive grants system that science, government and the public are proud of. Virtually every authority one speaks to refers to the constant level of $0.7 \%$ of GNP spent on pure and applied research (similar to the levels in Hungary and the Czech Republic) as evidence that much has been achieved. There has been a demonstrable increase in productivity and quality. The physics community shows its resilience by being prepared to discuss what physics means, with some physicists, including Professor Turski, saying it is "still too large" for what is needed for science. Speaking at last year's Pugwash seminar Evaluating Science and Scientists, his view is that the KBN is successful in maintaining science's credibility and support simply because it has a microscopic approach: there is no "major science policy" and funds are distributed more according to the value to science of individuals rather than on whether a topic is "useful" or in a "statistically defined mainstream". The paradox is that individual merit is generally evaluated and demonstrated in part by peers in terms of the variables and structures he probably dislikes.

\section{Schools and Conferences POLAND, 1994}

Ampere Workshop on Magnetic Resonances \& Microwave Absorption in the High- $T_{c}$ Superconducting Materials (Poznań, 10-13 April 1994); Inst. of Mol. Physics PAS, ul. Smoluchowskiego 17/19, PL-60-179 Poznań [+48 (61) $612407 / 674751$; htsconf@marta.ifmpan.poz. edu.pl]

4th Int. Symp, on Systems with Fast lonic Transport (10-14 May 1994, Warsaw); Contact: W. Jakubowski, Physics Inst., Warsaw Polytechnic, ul. Koszykowa 75, PL-00-662 Warsaw [tel./fax: - / +48 (2) 628171 ]

Interferometer '94 (Warsaw, 16-20 May 1994); M. Kujawinska, Inst. of Design Precise and Optical Instruments, Warsaw Univ, of Tech, ul. Chodkiewicza 8, PL-02-525 Warsaw Univ. Of Tech., ul. Cho

ISSRNS-2: Int. School \& Symp. on Synchrotron Radiation in Natural Science (Jaszowiec, 18-26 May 1994); K. Lawniczak-Jablonska, Inst. of Physics, al. Lotnikow 32/46, PL-02-668 Warsaw [- / +48 (22) 430926 ; jablo @ifpan.edu.pl]

17th Kazimierz Meeting on Elementary Particle Physics (Kazimierz, 23-27 May 1994); Z. Aduk, Inst. of Theo. Physics, Warsaw Univ., ul. Hoza 69, PL-00-681 Warsaw [+48 (2) $6283396 / 6219475$; kazcon@ fuw.edu.pl] 23rd Int. School on Physics: Physics of Semiconducting Compounds (Jaszowiec, 30 May-3 June 1994): T. Story, Inst. of Physics, Polish Acad of Sci., al Lotników $32 / 46$,

PL-02-668 Warsaw [+48 (22) $435626 / 430926$; PL-02-668 Wars

story@ifpan.edu.pl

Semi-Insulating III-V Materials (Warsaw, 6-10 June '94)

J. Katcki, Inst. of Electronic Tech., al. Lotników 32/46,

PL-02-668 Warsaw [katcki@opto.ite.war.pl]
Physics Education in Technical Universities (Cracow 27-28 June 1994); J. Niewodniczański, Fac. of Nuclea Phys. \& Technology, Acad. of Mining \& Metallurgy, al Mickiewicza 30, PL-30-059 Cracow [niewodnicz@novell. ftj.agh.edu.pil]

11th Int. Conf. on Solid Compounds of Transition Ele ments (Wroclaw, 5-8 July 1994); W. Suski, Low Temp. \& Structure Res., POB 937, PL-50-950 Wroclaw $2[+48$ (71) 350 21 / 4410 29]

ICM '94: Int. Conf. on Magnetism (Warsaw, 22-26 Aug. 1994); J. Morkowski, Inst. of Molecular Physics, ul. Smoluchowskieg 17/19, PL-60-179 Poznań [+48 (61) 674071 $674751]$

Int. Conf. on the Theory of Hadrons \& Light-front QCD (Zakopane, 15-26 Aug. 1994); St.D. Glazek, Inst. of Theo. Phys, Warsaw Univ, ul. Hoza 69, PL-00-681 Warsaw [+48 (2) 6283396 / 6219475 ; stglazek@fuw.edu.pl 16th Conf. on Applied Crystallography (Cieszyn, 22-26 Aug. 1994); D. Stroz, Inst. Fizyki i Chemii Metali, Univ Slaski, ul. Bankowa 12, PL-40-007 Katowice

18th Int. School on Theo. Physics: Interacting Electrons in Low-Dimensional Systems (Ustron, 28 Aug 4 Sept. 1994); E. Zipper, Inst. of Physics, Univ. of Silesia, ul. Uniwersytecka 4, PL-40-007 Katowice.

SSPCM '94: 3rd Int. Summer School on Theo. Phy sics: Symmetry \& Structural Props. of Condensed Matter (Poznat, 17 Sept '94): S. Walcerz, Mathematical Physics Div. IF UAM, Ul. Jana Matejki 48/49, PL-6 Poznań [+48 (61) 6686 51/ 6589 62; sspcm @ plpuam11 amu.edu.pl]

29th Zakopane School of Physics: Trends in Nuclea Physics (Zakopane, 5-14 Sept. 1994); W. Meczynski, Inst. of Nuclear Physics, ul Radzikowskiego 152, PL-31-342 Cracow [+48 (12) 370222 / 3718 81; meczynski@

ISFD-3: 3rd Int. Symp. on Domain Structure of Ferroelectrics \& Related Materials (Zakopane, 6.9 Sept. '94); Cz. Pawlaczyk, Inst of Molecular Physics, Polish Acad of Sci. Smoluchow (61) 612347 / 6845 24; isfd3@ marta.ifmpan.poz.edu.p I DRP '94: Conf. on Dielectric \& Related Phenomena (Zakopane, 12-16 Sept. 1994); A.B. Szymanski, Cracow Inst. of Tech., ul. Makowa 16, PL-30-650 Cracow I+48 (12) $555051 / 217577 ;$ zt przyby @ cyf-kr.edu.pll

10th Conf. on Solid \& Liquid Crystals - Materials Science \& Applications (Zakopane, 10-15 Oct. 1994) J. Zmija, Inst. of Tech. Physics, PL-00-908 Warsaw [+48 (2) $369731 / 362254$

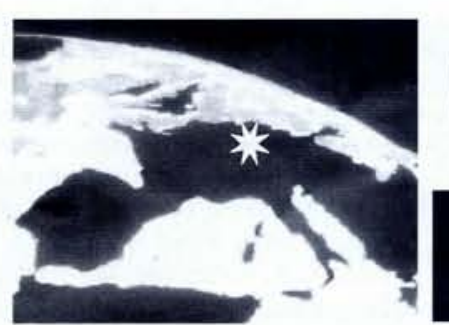

RAI Congress Centre Amsterdam, The Netherlands

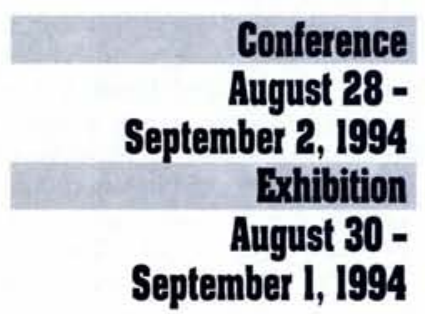

\section{CLEO®EUROPE-EQEC'94

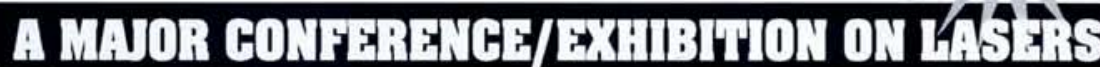

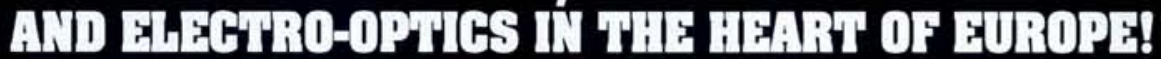

\section{INTERNATIONALLY RENOWNED SOCIETIES COMBINE FORCES}

The Conference on Lasers and Electro-Optics in Europe (CLEO/Europe) held in parallel with the European Quantum Electronics Conference (EQEC).

\section{COMPREHENSIVE TECHNICAL PROGRAM}

* A comprehensive technical program including basic \& applied research on, quantum physics, lasers, electro-optics, optoelectronics; systems engineering and applications.

* Educational short courses
INNOVATIVE APPLICATIONS FOR INDUSTRY

* A major exhibition with over 200 leading companies.

* The latest systems, devices, and methods of production, testing, and monitoring.

* Innovative Application Seminars.

\section{LASERS, ELECTRO-OPTICS, \& OPTOELECTRONICS FOR: \\ * SCIENCE \\ * RESEARCH \& DEVELOPMENT \\ * ORIGINAL EQUIPMENT MANUFACTURERS \\ * eND USERS}

\section{For additional information:}

Sponsored by:

The European Physical Society

Quantum Electronics \& Optics Div.

IEEE Lasers and Electro-Optics Society

Optical Society of America
CLEO/Europe-EQEC'94

c/o Institute of Physics

Meetings \& Conferences

Department

47 Belgrave Square

London, SW1X 8QX, UK

$\mathrm{FAX}+44(0) 712596002$
In North America:

CLEO/Europe-EQEC'94

c/o IEEE/LEOS

445 Hoes Lane

Piscataway, NJ 08854, USA

FAX (908) 562-1571 